выходя из дома, но при этом, работая сообща, а затем представить его своим одноклассникам.

Описанная стратегия и была применена мной при прохождении педагогической практики в одной из школ. Учащиеся получили несколько тем для проектов на выбор и объединились в группы по пять человек. Для упрощения работы мы предложили несколько ресурсов для создания онлайн-проектов. Ученики охотно взялись за выполнение задания и изучение новых ресурсов - это еще одно преимущество сайтов для создания онлайнпрезентаций, так как новое всегда интересно.

Наблюдая за работой учащихся, было определено, что большинство используют два сервиса для создания презентаций: Canva и GoogleDocs. B конечном итоге у каждой группы получились яркие и интересные проекты. Данное наблюдение позволяет сделать вывод, что из всего перечня описанных ресурсов, наиболее удобными для работы оказались именно эти два.

Для учителей-предметников очень важно включать в свою работу метод проектов, так как это помогает расширить знания учащихся по предметам на более высоком уровне. Через проектное обучение осуществляется развитие творческих потенциалов учеников. Кроме того, проектная деятельность позволяет объединить знания детей по нескольким предметам сразу, например, по английскому языку и информатике. Создавая проекты по английскому языку, учащиеся развивают коммуникативную компетенцию, так как работают сообща, а также культурологическую компетенцию, так как чаще всего проекты направлены на изучение культуры изучаемого языка. При этом учащиеся готовятся к жизни в информационном обществе, к поиску информации в сети Интернет, а также к взаимодействию в режиме онлайн. «В современном мире нужно не просто уметь находить информацию, но и уметь анализировать её и оценивать. Сейчас из-за обилия информации это сделать сложно даже взрослому человеку, не то что ребёнку» [3: С. 175]. Именно поэтому необходимо включить учащихся в процесс освоения интернет ресурсов. Именно для достижения описанных задач и развития данных компетенций мы рекомендуем использовать в проектной деятельности ресурсы для создания онлайн-презентаций.

$$
* * *
$$

1. Евдокимов, Р. Н. Интернет сервисы для организации практических занятий студентов / Р. Н. Евдокимов // Наука и просвещение: актуальные вопросы, достижения и инновации : сборник статей Международной научно-практической конференции, Пенза, 28 февраля 2020 года. - Пенза: "Наука и Просвещение" (ИП Гуляев Г.Ю.), 2020. - С. 106-108.

2. Панова, В. Н. Проектная деятельность на уроках английского языка / В. Н. Панова // Научное и образовательное пространство: перспективы развития : сборник материалов Международной научнопрактической конференции, Чебоксары, 06 ноября 2020 года / ФГБОУ ВО «Чувашский государственный университет им. И.Н. Ульянова»; Актюбинский региональный государственный университет им. К. Жубанова; Кыргызский государственный университет им. И. Арабаева. - Чебоксары: Общество с ограниченной ответственностью "Центр научного сотрудничества "Интерактив плюс", 2020. - С. 51-53.

3. Пичужкина, Д. Ю. Использование сервисов web 2.0 в образовании / Д. Ю. Пичужкина, Е. С. Смекалова, А. В. Поначугин // Вопросы педагогики. - 2019. - № 4-2. - С. 175-178.

4. Полевая, Н. М. Инструменты для активной образовательной онлайн-деятельности в вузе (на примере направления подготовки 39.03.02 "социальная работа") / Н. М. Полевая, В. В. Ситникова // Вестник Амурского государственного университета. Серия: Гуманитарные науки. - 2021. - № 92. - С. 81-86.

\title{
Чеканова П.О., Яриков В.Г. \\ Онлайн редактор ментальных карт для изучения простого предложения на уроках русского языка
}

Волгоградский государственный сочииально педагогический университет (Россия, Волгоград)

doi: 10.18411/trnio-12-2021-285

\section{Аннотация}

Как с помощью ментальных карт помочь развитию творческого мышления, овладению навыками по тому или иному предмету, а также созданию условий для самореализации творческого потенциала учеников? Каким образом ментальные карты 
способствуют визуализации мышления и структурирования мыслей? На эти вопросы мы ответим в данной статье.

Ключевые слова: ментальная карта, онлайн редактор, простое предложение, метод ментальных карт, интеллект-карта.

\section{Abstract}

How can mental maps help develop creative thinking, master skills in a particular subject, as well as create conditions for self-realization of students' creative potential? How do mental maps contribute to visualizing thinking and structuring thoughts? We will answer these questions in this article.

Keywords: mental map, online editor, simple sentence, method of mental maps, intelligence map.

Метод ментальных карт представляет собой определенную технику визуализации мышления, в основе которой лежат записи. Такие карты имеют и другие названия, например, интеллект-карта, карты разума, карты ума. Помимо ассоциативных связей между записей, важным элементом и основной мыслью методики становится рисунок, выделенный в самом центре, от которого и идут ответвления (шаги, идеи, мысли, задачи). Большое воздействие использование ментальных карт оказывает на развитие «радиального мышления», где отправная точка и является центральным объектом [2, с.13].

Образовательная система последнее время сильно меняется, что связано не только с новыми требованиями к результатам образования, но и с осознанием того, что нужно воспитать в ученике личность. В последние годы метод ментальных карт всё чаще встречается в организации образовательной деятельности учителей, а сервисов для создания ментальных карт становится всё больше. Следует понять, какой онлайн редактор самый удобный для педагогической деятельности.

Основная цель создания ментальных карт - помощь мышлению и его развитие. В образовательном процессе данный метод играет одну из главных ролей - являются средством эффективного конспектирования материала, подготовки по определенной теме, выполнению домашнего задания, решению творческих задач.

При работе над ментальными картами, учащиеся демонстрируют не только свои знания, но и умения воспринимать, обрабатывать и представлять схематично главную мысль, проблему, тему, составляющие компоненты и др. На уроках русского языка метод ментальных карт является наиболее эффективным для запоминания различных правил [3, c.23].

Можно выделить некоторые преимущества применения ментальных карт на уроках русского языка:

1. экономия времени, предусмотренного на написание конспектов правил;

2. наглядная логика, структура и взаимосвязь материала;

3. задействован творческий потенциал учащихся;

4. улучшение качества пройденного материала.

Необходимо учитывать возрастные особенности учеников, так, в 5-6 классе рекомендуется использовать метод упрощенной ментальной карты с применением образов и символов преимущественно, а в 7-11 класс ученикам по силам составить развернутую ментальную карту в соответствии с приобретенными знаниями, умениями и навыками выделять и анализировать основную информацию [5, с.30].

Созданные самостоятельно или учителям ментальные карты в дальнейшем являются шпаргалкой ученикам, которую можно использовать как на уроках, так и вне школы для выполнения домашнего задания. Условием эффективности ментальных карт - регулярное повторение, возвращение к картам в новом учебном году, возможность дополнения карт по ходу изучения нового материала по той же теме. 
На сегодняшний день существует множество онлайн сервисов для создания ментальных карт. Для сравнения я выбрала три редактора, которыми часто пользуюсь сама: iMindMap, Mindmeister и Mapul. Предлагаю сравнить их:

Таблица 1

Сравнение онлайн сервисов для создания ментальных карт

\begin{tabular}{|c|c|c|}
\hline Онлайн сервис & Плюсы & Минусы \\
\hline $\begin{array}{c}\text { Mindmeist } \\
\text { www.mindmeister.com/ru }\end{array}$ & $\begin{array}{l}\text { - Понятен в работе } \\
\text { - Лаконичный дизайн } \\
\text { - } \text { Есть бесплатный тариф }\end{array}$ & $\begin{array}{c}\text { На бесплатном } \\
\text { тарифе можно } \\
\text { создать не более } 3 \\
\text { карт. }\end{array}$ \\
\hline $\begin{array}{c}\text { iMindMap } \\
\text { https://app.imindmap.com/ }\end{array}$ & $\begin{array}{c}\text { - } \quad \text { Яркий, нестандартный, красочный, } \\
\text { творческий дизайн } \\
\text { • } \quad \text { Функичиональный режим презентаичий }\end{array}$ & $\begin{array}{c}\text { Нет бесплатного } \\
\text { тарифа, только } \\
\text { тестовый период на } \\
7 \text { дней } \\
\text { Не самый простой в } \\
\text { работе } \\
\end{array}$ \\
\hline $\begin{array}{c}\text { Mapul } \\
\text { https://www.mapul.com/ru }\end{array}$ & $\begin{array}{c}\text { • Яркие ивета дизайна } \\
\text { - } \quad \text { Eсть бесплатный тариф, но только на } \\
\text { создание одной МК }\end{array}$ & $\begin{array}{c}\text { Достаточно } \\
\text { непростой } \\
\text { интерфейс, сложно } \\
\text { было понять, как } \\
\text { удалить и добавить } \\
\text { новое ответвление }\end{array}$ \\
\hline
\end{tabular}

Я использовала онлайн редакторы при разработке ментальных карт для изучения простого предложения на уроках русского языка. При использовании Mindmeister у меня получилась следующая ментальная карта (Рис.1).

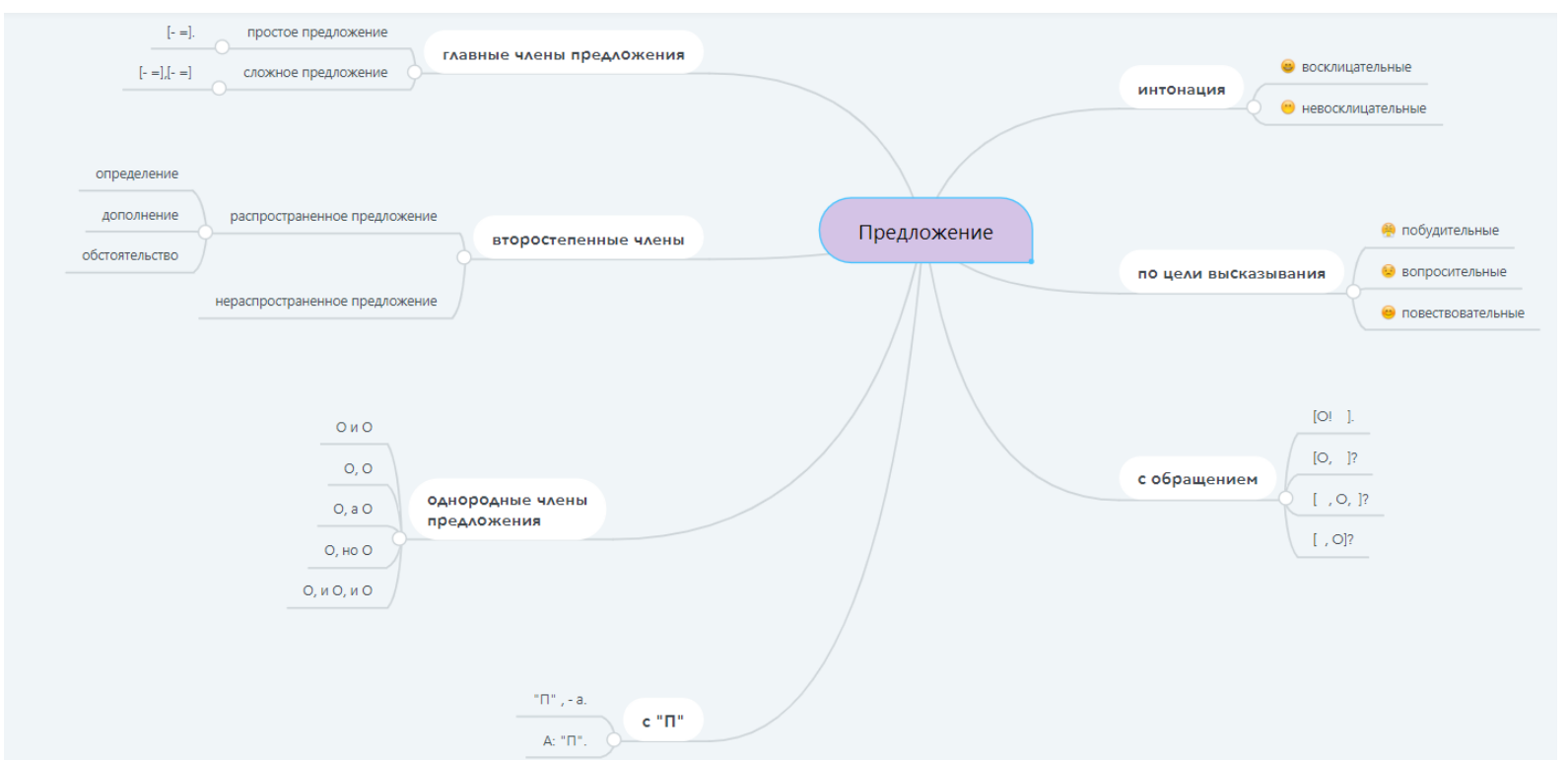

Рисунок 1. Ментальная карта в онлайн сервисе Mindmeister

Как видно из рисунка, карта выглядит лаконично и кратко, она не очень яркая, но для учеников такая карта, на мой взгляд, будет понятна лучше. Так как карту из этого редактора можно сохранить в PDF-формате, её следует распечатать и раздать детям, а они уже на своё усмотрение раскрасят пункты. Здесь мы сможем раскрыть творческие способности детей, а также заинтересовать их в данной теме, ведь во время подбора цветов и разукрашивания, ученики будут читать материал на ментальной карте и запоминать его.

При создании ментальной карты у меня не возникло проблем, я не потратила много времени, потому что интерфейс был понятен. Все команды на сервисе быстро исполнялись, именно поэтому я отдаю своё предпочтение онлайн редактору Mindmeister.

Используя iMindMap, у меня получилась такая ментальная карта (Рис.2). 


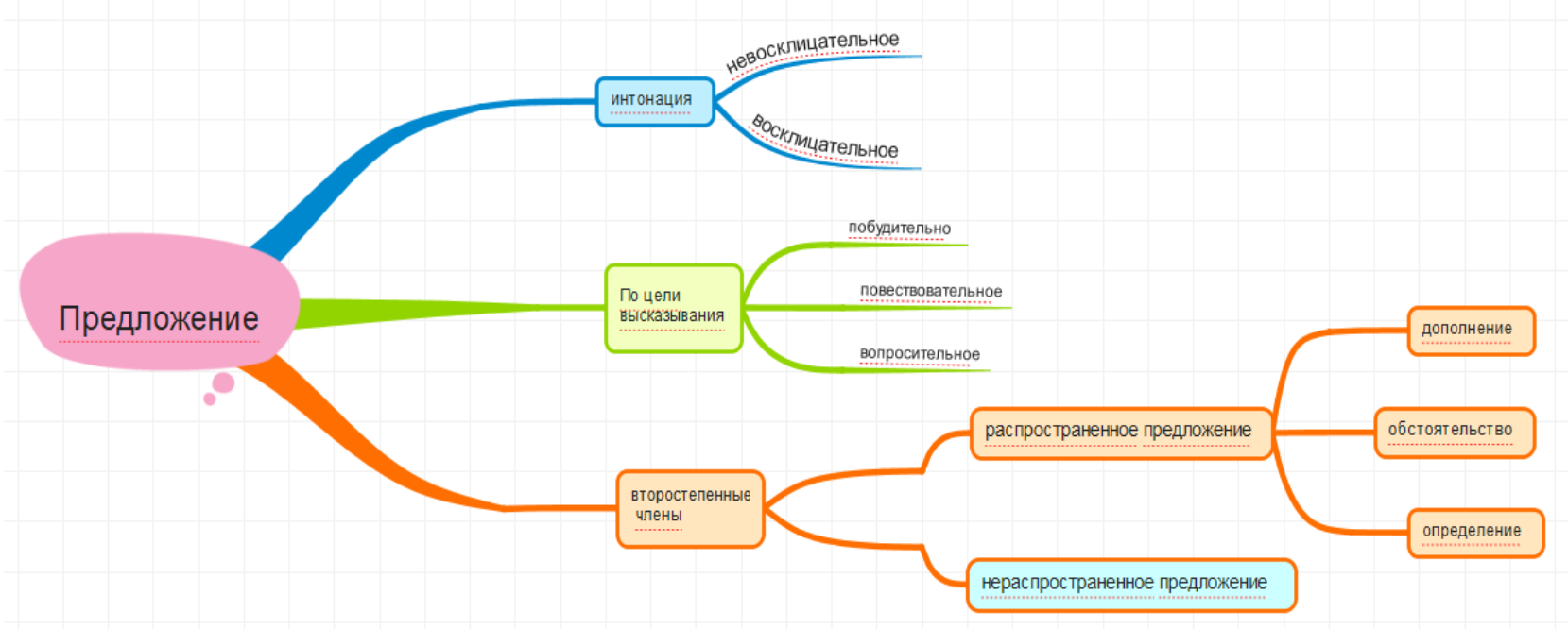

Рисунок 2. Ментальная карта в онлайн сервисе іMіndMap

Здесь сразу привлекают внимание красивый, яркий дизайн. Эту ментальную карту можно будет вывести на экран, чтобы заинтересовать детей. При её создании возникли небольшие трудности с пониманием, какой инструмент использовать, потому что сервис на английском языке.

Применение метода ментальных карт на уроке русского языка по теме «Простое предложение» способствует лучшему запоминанию теоретического материала, а также дает возможность использовать наглядную подсказу при выполнении заданий, что способствует формированию навыка анализа ментальных карт.

Третьим онлайн редактором, который я рассмотрела, стал Mapul. Составленный ниже фрагмент ментальной карты (Рис.3) можно продолжить или составить отдельные карты по каждому разделу, посвященному данной теме.

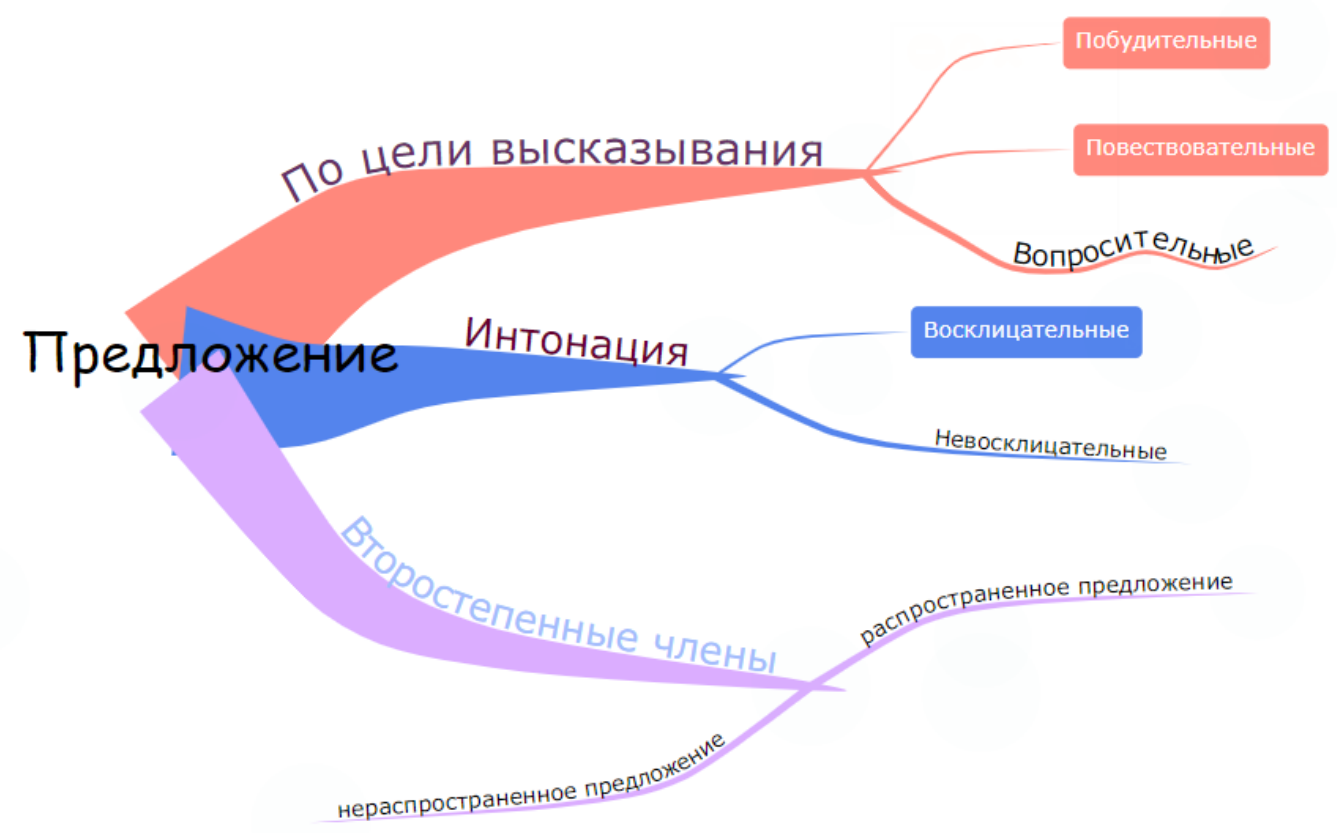

Рисунок 3. Ментальная карта в онлайн сервисе Mapul

В данном сервисе есть пробная бесплатная версия, где можно создать одну ментальную карту. Вернее будет сказать - переделать, потому что сервис предоставляет 
доступ к множеству шаблонов ментальных карт. Можно выбрать тот, что подойдет именно Вам и доработать его.

Огромным плюсом использования ментальных карт на уроках русского языка является их долгосрочность. МК можно разделить на несколько маленьких, что позволит углубиться в тему, можно дополнять её при изучении темы. В рамках изучения простого предложения, можно отметить, что составление метальной карты может быть как самостоятельным заданием, так выступать в роле проверочного задания. Работа может быть построена также с использованием анимация, цветового выделения [6].

При работе с ментальной картой преобладает познавательная, творческая и поисковая деятельность, что способствует эффективному усвоению полученных знаний. Создание, разработка ментальных карт при подготовке к занятию помогает педагогу увидеть все взаимосвязи между элементами преподаваемой дисциплины. Создание собственных ментальных карт является для детей возможностью: выявить свои пробелы в знаниях по учебному предмету, научиться самостоятельно работать с информационными материалами, развить личностные качества, пространственное и образное мышление, уверенность в своих силах и творческих способностях.

Метод ментальных карт должен практиковаться в школе, так как повышает эффективность получения знаний. Сейчас, к счастью, возможность составления электронных ментальных карт довольно высока, так как программных обеспечений, в которых можно составлять карты для уроков, есть большое количество, и каждый сможет выбрать понравившийся ему сервис.

$$
* * *
$$

1. Бадерина А. А. Перспективное использование метода ментальных карт в образовательной среде // Безопасное детство как правовой и социально-педагогический концепт. - Пермский государственный гуманитарно-педагогический университет, Пермь. - 2019. - С. 196-197.

2. Балан И. В. Использование ментальных карт в обучении / И. В. Балан. - Текст: непосредственный // Молодой ученый. - 2015. - № 11.1 (91.1). - С. 58-59.

3. Воробьева В. М., Чурикова Л. В., Будунова Л. Г. Эффективное использование метода интеллект-карт на уроках: Методическое пособие. - М.: ГБОУ «ТемоЦентр», 2013. - 46 с.

4. Пуляевская А. М., Соловьева Е. А. Способы и инструменты визуализации информации // Электронное обучение в непрерывном образовании. - 2016. - № 1. - С. 349-354.

5. Симонова М. В. Использование ментальных карт в деле обеспечения качества знаний на разных этапах обучения // Научные исследования в образовании. - 2008. - №6. - С. 54-63.

6. Хакимов Д. Р. Применение в учебном процессе ментальных карт // Образовательные ресурсы и технологии. - 2016. - №1 - С. 3-8.

7. Яриков В. Г. ., Чунаков С. А. Использование метода интеллект-карт при организации дискуссии на уроках изучения современной литературы // Научно-методический электронный журнал «Концепт». - 2018. - № V2. - C. $1-6$.

\title{
Abdullayeva S.N. Assessment of the contribution of adjectives to stylization
}

\author{
Nakhchivan University \\ (Azerbaijan, Nakhchivan)
}

doi: 10.18411/trnio-12-2021-286

\section{Abstract}

In this study, the most important features of adjectives and adjective phrases were examined in terms of structure and meaning. The aim of the study is to highlight the prominent types, elements, and frequency of use of the adjective in the work we examined, to determine and reveal the decisive role of adjectives in terms of style, to indicate what meanings the words or phrases used as adjectives give to the noun elements they come before. The article deals with the adjective phrases formed by the descriptive, the attributive, demonstrative, uncertainty, numeral adjectives.

Keywords: adjectives, word, grammar, feature, adjectival. 